Article

\title{
ERP Perspective Analysis of PSS Component and Decision-Making
}

\author{
Meina Zhao ${ }^{1, *}$, Jing Wang ${ }^{2}$, Heng Zhang ${ }^{2}$ and Gang Zhao ${ }^{3}$ \\ 1 School of Economics and Business Administration, Heilongjiang University, Harbin 150080, China \\ 2 School of Economics and Management, Beihang University, Beijing 100191, China; jim08@buaa.edu.cn (J.W.); \\ zh19930429@163.com (H.Z.) \\ 3 School of Mechanical Engineering and Automation, Beihang University, Beijing 100191, China; \\ zhaog@buaa.edu.cn \\ * Correspondence: 2018056@hlju.edu.cn
}

Received: 18 December 2018; Accepted: 8 February 2019; Published: 18 February 2019

\begin{abstract}
This paper has developed a neuromarketing framework measuring the relationship between products and services in product-service systems (PSSs), particularly regarding its impact on PSS decision making. We divided the PSSs into different levels of product and service combinations in order to identify the impact of the various elements in PSS on decision making, particularly the key factor that induces significant variation in the purchase rate. The experiments showed the neural mechanisms behind the value perception of PSSs; this has been indicated by the appearance of N170, which is related to the cognition processing of familiarity and similarity. It is concluded that the perceived value of the product-oriented PSS is mainly determined by the product attribute, as the promotional effect of service has been clarified. The results explain the psychological and neurological activities that take place when consumers are browsing product-service bundles, which may help corporations better understand the relationships among the components in product-service bundles, providing insight for PSS innovation and service design.
\end{abstract}

Keywords: product-service system; event-related potentials (ERPs); decision making; perceived value

\section{Introduction}

Consumer cognition and emotion induction focus on the product and service combination provided by online shopping platforms, which influences consumers' online purchase decision-making. Online shopping platforms have been able to provide consumers with product and service combinations, such as JD.com and Taobao.com in China; thus, consumers can choose the service content related to the product just as they choose the product attributes. Product-service systems (PSSs) may integrate the design, implementation, and provision of product-service bundles as options for the consumer [1,2]. Many studies have investigated designing, developing, and delivering PSSs to the final user from a marketing perspective [3-5]. Product-service systems (PSSs) may create value by combining a product and a service in order to attract attention in manufacturing [6-8], which may be associated with customer requirements [9]. It is useful for the sellers to prompt the perceived value when customers are buying and utilizing a product or service [10], especially the product-service bundles. Many manufacturers as well as online shopping platforms are striving to offer attractive value-added PSSs to their customers [11,12]. While the service and product could be part of the provided value in PSSs, sometimes the value may be substituted [3,4]. The PSS providers are required to adopt a suitable strategy for combining and designing products and services. In addition, a product should be designed based on the customer demand, while the online shopping platform should be 
capable of comprehensive and attractive product-service bundles provision, formulating a PSS with continuous and dynamic optimization. Service is one of the most distinctive and flexible elements in a PSS. It can easily be modified and adjusted within the PSS, and may influence the total value of the combination of products and services. Although customer cognition is essential for realizing value, previous research has not compared the unique components that affect the PSS's perceived value and decision-making. If the substitutes or complements between products and services could be confirmed, it may offer much guidance for PSS optimization. However, the consumer's understanding of the relationship between product attributes and service in a product-service bundle is still unclear, especially the unique role of the element in a certain product-service bundle. Since the methods used to evaluate the feasibility of new businesses vary with the characteristics of the business, the evaluation methods for each product-service bundle might need to be modified to reflect the unique nature of the combination design of products and service within a product-service-bundle. Designers of a product-service bundle require methodologies and tools for visualizing the buying process of customers and their needs. Given the difficulties of cognizing a product-service bundle for customers, as well as the limited methodologies and tools that are available for this purpose, this issue is still not widespread in the academic community. In addition, the normative measurement of product-service bundle value perception still needs to be explored. Since the success of the PSS largely depends on understanding and satisfying different requirements, the psychology and neural mechanism of customers' PSS preferences and decision-making should be investigated. It is necessary to further extract the product-service bundle decision-making mechanism behind users' behavior, which will enhance the depth of requirement identification and the innovation of PSS design.

Neuroscience research has guided complex human decisions by demonstrating the role of implicit and automatic processes $[13,14]$, which can be connected with psychology and management regarding the use of customer behavior. Customer cognitive and emotional processes may predict the potential individual requirement in PSS decision making. When people face the moment of economic management and decision making, the brain activity can be recorded in order to address the challenge of understanding consumer decision making. Since customer behavior cannot be readily determined from the data, a potential new tool has been provided by the neuroscience. These tools may be effective in indicating the perceived value of the combination of components in a PSS $[15,16]$. Cognitive neuroscience can identify the mechanisms that drive homogeneous or heterogeneous output across individuals. The same can be done for product-service bundle decision making, based on the unique preference of components in PSSs. An explanation of the neural mechanisms underlying customer-perceived value evaluation may both present understanding of the cognitive and emotional processes that guide personalized customer needs in customer decision making, and provide new approaches in the study of product-service bundle design and innovation. Specifically, significant advances have been made in identifying the neural mechanisms underlying decision-making processes, which may be applied to this study. Therefore, to better demonstrate the roles of elements and design in meeting customer demand regarding PSSs, the following questions have been addressed in the research: Is it better to offer superior product and service levels in product and service bundles? What is the optimal combination of product and service to offer? What is the key role of the components in product-service bundle decision making? This study aims to identify the customer-perceived value of the combination of products and services that influence customer cognition and emotion, from the viewpoints of neuromarketing and psychology, indicating the component sensitivity of customer requirements and the perceived value of the component within the PSS during customer decision making. Additionally, this manuscript investigates the interpretation of how the service matches the product attribute and the unique factors of product-oriented PSS decision making. Since the product-service bundle is the output of the PSS, the customer sensitivity regarding the product-service bundle component may guide PSS innovation. The conclusion offers effective and innovative PSS solutions based on customer requirements. 


\section{Literature Review and Hypothesis}

\subsection{Product-Service Bundle Design}

A product and a service have been combined as a whole provision in order to provide a solution for the customer [1,2]. In the process of manufacturing servitization, product-service systems (PSSs) bundling a physical product and a service may increase the perceived value and provide an attractive experience to customers $[4,5]$. The relationship between product and service in PSS has been interpreted through the description of different levels of PSS. Two or more separate products together have been described as a bundling sale in the market [11], which may create an extraction of consumer surplus, as well as products bundled with service [17]. The different combinations of products and services may play different roles in a PSS, as well as in customer demand. In product-oriented PSS business models, the cooperation provided a service related to the product [18], such as maintenance or upgrading. During the purchasing decision, the customers gain the ownership of the product, while the services are capable of facilitating the product performance. The service attached to a product manages the delivery and effectiveness of the product over a given period of time, which are difficult to exist independently and are closely related to the product. Since the variety of services plays an important role in improving the competitiveness of products, there is a need to identify how to effectively configure the services with the diversity product in the development of a PSS proposition [19-21]. Previous scholars provided the strategy for manufacturers who design bundles for a product with after-sale service; this strategy was focused on the service competitiveness, and how to match the after-sales service $[17,22]$. As the two distinct objects in product-service bundle, products and services have the typical characteristics of heterogeneity [21,22]. However, they did not study the impact of different levels of product and service on perceptions of the product-service bundles. Furthermore, the service requirements involve considerable human perceptions and judgments, leading to ambiguity and subjectivity in the process of product-service bundle requirement analysis [23]. It is necessary to address customers' product-service bundle preferences adequately.

\subsection{Neuroscience and Decision-Making}

According to identifying the neural mechanisms, neuroscience has played a key role in understanding customer decision-making processes [24,25]. Furthermore, recent research has provided a new method to address the underlying consumer decision-making process: event-related potential (ERP) experimentation. Since ERP techniques are able to identify the brain activity that corresponds to preference measures and emotion evocation, this demonstrates an ability to identify the precise computations taking place in the brain [26]. Some studies have shown that late positive potentials (LPPs) in brain activity are induced by pleasant and unpleasant stimuli [27]. LPPs are specifically enhanced for pictures or words that are more emotionally intense. Due to individual unique cognitive processes, neuromarketing is an interdisciplinary discipline that combines marketing and its effects on brain cognitive and emotional processes. The study of customer behavior has indicated the internal motivation of customer decision making, in order to promote objective and accurate strategies. Current studies have attempted to understand how consumer choice processes are modulated by various component changes, indicating the cognitive or emotional involvement during the purchasing process. Many marketing stimuli, such as product attributes, brands, and services have been selected in previous ERP studies. For instance, the LPP components of event-related potentials (ERPs) were observed to evaluate consumers' emotional valence evoked by the products and services stimuli. Both the products and the services induced LPP in the frontal and central regions, which showed and confirmed emotional evocation processing when online buying decisions are made [27]. The previous study has confirmed that a high emotional value service elicited a greater LPP in the left frontal regions than a low emotional value service [26]. Customers with different cognitive competencies show different cognitive and emotional processes during online service decision making, as observed by the different amplitudes in the ERP experiment [26]. Therefore, the valuation of customers' cognitive 
and emotional processes may be indicated by the evocation of value signals in the human brain. That mechanism may be presented in the process of value perception and the product-service bundle decision-making process associated with consumption. The decision making of the consumer is not only related with the performance of the product, brand, design, advertising, product aesthetics, and service quality [28-30], but also the relationships among them. Prior neuromarketing research has mostly examined the impact of product attributes, preference persistence, purchase intention, brand choice, and product and service value in PSS decision making [31,32]. However, it is necessary to provide an understanding of the neural mechanism process underlying the customer-perceived value of PSS and the component relationship in PSS.

\subsection{Hypotheses}

The innovation and development of a product or a service generates new problem due to the unique requirements for PSSs. Product content has been regarded as the key measure of customer satisfaction in many customer requirement studies. Compared to the separate physical products or services, the PSS generally requires the design of a portfolio of products and services. However, the criteria for customer satisfaction may include other elements in the purchasing process of PSS. For instance, customers may focus on the anticipated consequences and potential value that are created during the buying and utilizing phases. Previous studies have indicated that the PSS requirements may be divided into the product requirements and service requirements. However, the interaction between the products and services may affect the customer priority requirements of products and services. It is important to indicate the impact of component sensitivity on PSS decision making, and analyze whether the promotion of the purchasing rate generated different levels of elements regarding the PSS. The PSS is an organization, according to the relationship between the product and service component in a PSS. The change of any component in a PSS, such as the improvement or decrease of the product or service level, will make an impact on the decision making regarding the PSS purchase.

Customer demand for products has been divided into basic demand, expectation demand, charm demand, undifferentiated demand, and reverse demand according to the Kano model, which may be defined by the sensitivity of demand to customer satisfaction [33]. For instance, when the quality of basic demand is greatly improved, the change range of consumer satisfaction is relatively small. Meanwhile, if the quality of charismatic demand is improved, the degree of consumer satisfaction will be greatly improved [34]. However, due to the classification of quality categories mainly being based on the Kano questionnaire, it is still difficult to eliminate the strong subjectivity of the evaluation. Priority is given to the physical product design in product-service bundles, particularly in a product-oriented PSS. The specific service function is determined by the physical product and driven by the design of the physical product in the product-service bundle relationship. In a product-service integration design, the customer needs of products and services, particularly the collocation of products and services, should be jointly realized. The product function is a hierarchical decomposition of a product, which may provide customers with the corresponding physical structure. Considering the different degrees of correlation between products and services, the service function is dependent on its relationship with the product. The service associated with the support of some physical products, such as maintenance service, can be describe as the functional service [35]. The functional service is based on the requirements of the customer, in order to prompt the value and conditions of relating products. The product function can be realized by presenting the use value in a physical form. This study focuses on a method to investigate product-service bundles driven by customer requirements as well as a customer requirement-oriented product-service combination design method to address the priority issue of the design of products and services. Building upon these findings, the first hypothesis in this study is as follows:

H1: The consumer sensitivity on product components is a priority to service components in a product-oriented PSS. 
Event-related potential (ERP) measures collected from the human scalp may present participants' unique cognition of certain stimulus, which is different from others in the experiment. N170 may be evoked in the occipito-temporal brain region at above $170 \mathrm{~ms}$ after visual presentation, especially the presentation of face pictures [36]. When the face-related stimuli were presenting, N170, peaking at approximately $170 \mathrm{~ms}$ post-stimulus, was detected as a negative component. Then, scholars also confirmed that face stimuli elicited a larger amplitude of N170, as well as the faces of structural disruption or inversion, in comparison to other stimuli. When the participants were presented by the cognition of face-related characteristics, the face-related stimulus may evoke the N170, indicating similarity in the cognition of individuals and expected cognition [37]. Scholars have demonstrated that not only faces but also Chinese characters may generate an N170 component. One previous study indicated that $\mathrm{N} 170$ is not constant for facial representation, suggesting that the cognitive tasks may significantly affect the N170 amplitude [38]. The N170 amplitude may be a common reaction to highly familiar visual stimuli [38]. For instance, scholars compare the N170 component elicited by human faces with the ERPs elicited by ape faces, birds, cars, and items of furniture, in order to explore face specificity in visual processing.

Additionally, scholars found that the participants with training who become experts in the field regarding the stimuli may evoke larger-amplitude N170 components. The different N170 amplitude has been motivated by participants who are familiar with the stimuli, showing the early cognition processing stage of the expertise. Meanwhile, the participants' lesser-known stimuli would present a lower N170 amplitude [36]. The results demonstrated the different neurological mechanisms implicated in the cognition of faces versus other objects, suggesting that the other objects are more sensitive to strategic manipulation and attention. The N170 components can be induced not only by face stimuli but also by stimuli such as cars, houses, shoes, furniture, tools, road signs, flowers, and printed words [37]. The larger N170 elicited by faces may be influenced by their expertise in recognizing faces [38]. The customer's preferences and requirements may be presented by the similarity in the cognition information of the individual, which may generate the ERP component, such as N170. The N170 may be associated with category information processing: the more similarity and familiarity with the visual mechanism, the larger the amplitude. Therefore, the last hypothesis in this study is as follows:

H2: The N170 amplitudes evoked by product-service bundles with superior product component levels will be greater than those of PSS with inferior product component.

The model of stimulus-organism-response (S-O-R) has indicated that an individual's response (R) was driven by their internal states $(\mathrm{O})$, which was generated by an encountering stimulus (S) [39]. Previous studies have proposed that the individuals' approach or avoidance behavior may be connected with their cognitive and emotional states, while the individuals' states were influenced by external stimulus, such as economic and social stimuli. In addition, the research of consumer responses to variations of formats of products, services, and online stores has supported the validity of that model. For instance, according to the model of stimulus-organism-response, Mehrabian proposed a relationship between emotions and customer behavior. Scholars have proposed that the consumers' cognitive and affective states generated by the product performance may prompt the purchasing behavior.

These authors confirmed that the product attributes may modify customers' cognitive and affective states. This may have major influences on approach behavior, showing that attitude and pleasure influence approach-avoidance behavior directly. Applying the S-O-R model to the buying decision making, they built the model using attitude and pleasure toward products reflecting both the cognitive and affective states. While previous research has shown that online service decisions were influenced by customer emotion involvement, it is important to indicate the customer cognition and emotional state generated by PSSs, which may help identify the customer's deep requirements. 
Consumers' decision-making processing is related to cognitive states. The favorable or unfavorable attitude to the product refers to the cognitive state concerning acquisition or avoidance information $[40,41]$. When the customers evaluate the perceived value of the PSS, the cognitive state regarding the requirement of a product and a service may play a great role in the decision making. Furthermore, a study of the impact of the retail atmosphere on product marketing confirmed that the approach behaviors were prompted by the positive emotions elicited by the environmental atmosphere [42-45]. The present study may investigate how PSSs influence consumer responses, which may differ from the attitude for a single product and service decision-making. Building upon these findings, the third hypothesis in this study is as follows:

H3: The positive cognitive states may prompt the consumer purchase rate during the decision process of product-oriented PSSs.

\section{Methodology}

\subsection{ERP Experiment Design}

The neuromarketing studies in this paper collected data from individuals when stimuli were presented, and the data analysis followed certain steps. In order to compare activations across participates and stimuli types, the brains were spatially normalized to a template brain so that the spatial orientation may be compared and transformed with the stimuli type. A continuous recording was broken into event-locked epochs based on product-service bundles with superior levels of product and service, product-service bundles with superior levels of product and inferior levels of service, product-service bundles with inferior levels of product and superior levels of service, and product-service bundles with inferior levels of product and service. The knowledge of the localization of brain functions was then applied to analyze the development of consumer behavior and product-service bundle value perception. E-prime also collected all of the behavioral responses to verify the results; for instance, the relationship among customer response times and the cognitional valance of product-service bundles was examined. Therefore, the event-related potential (ERP) study reported presented the cognitive process related to the product-service bundle that was available for purchase.

\subsection{Subjects}

In order to address the role of N170-like neurophysiological responses during product-service bundle decision making, we designed an online shopping experiment. This study sought young, university-educated citizens as its subjects. Twenty-four subjects (nine female) participated in the study. The ages of participants were between 20-30 years old $(M=25)$. The subjects were asked to provide their demographic information and their experience of purchasing products and services online in the pre-test. The selected 24 subjects had the experience of purchasing products and services online in order to ensure the validity of the experiment. Due to the computer failure or excessive electroencephalogram (EEG) artifacts, the data from two subjects were excluded from analysis. Then, 22 participants were left in the final sample. The participants came from the School of Economics and Management at Beihang University. The subjects met the requirement of the EEG experiment. We informed the participants of the task and EEG procedures. All of the participants provided written consent and reviewed the research protocol, which was approved by the Academic Board of the University. We employed a single-factor design with product and service combination. The product component and service component in the product-service bundle were varied and divided into high and low levels. The product and service combination served as the independent variable in the experiment, while the purchase rate of the PSS, decision time, and the ERP amplitude served as the dependent variables. 


\subsection{Stimulus Materials and Procedure}

With regard to product-service bundle provision in China, we suggested categorizing product-service bundles into the following four scenarios: superior product attribute and superior service level (Product-service bundle 1); inferior product attribute and superior service level (Product-service bundle 2); superior product attribute and inferior service level (Product-service bundle 3); and inferior product attribute and inferior service level (Product-service bundle 4). According to the field survey of traditional Chinese manufacturers and the Jingdong Mall website, particularly regarding the definition and classification of a PSS, experimental materials were selected, which comprised three categories of electronic goods: mobile phones, single-lens reflex (SLR) cameras, and hard disks. Experimental materials were selected for electronic goods undergoing manufacturing servitization in China, particularly online shopping on the Jingdong Mall website. Shopping websites present products related with service, such as comprehensive broken screen coverage for one year and a new screen warranty service provided with mobile phones.

According to the arrangement with the Jingdong Mall website, two levels of product content (superior and inferior), and two levels of service (superior and inferior) were presented (in Chinese characters) from the four different product-service bundles. Each product-service bundle had $4 \times 4=16$ product and service portfolios, which would be selected by the participants. The product and service combination for each product-service bundle were presented randomly, and a total of 48 trials were presented. Different product-service bundles were provided randomly in the experiment. The presentation of product and service combination lasted for $2000 \mathrm{~ms}$, and then a question regarding the buying decision lasted for $4000 \mathrm{~ms}$ to allow for product-service bundle adjustments. The experiment procedure is shown in Figure 1. Subjects made the purchasing decision making in a specialized laboratory following the rules of the EEG experiment.

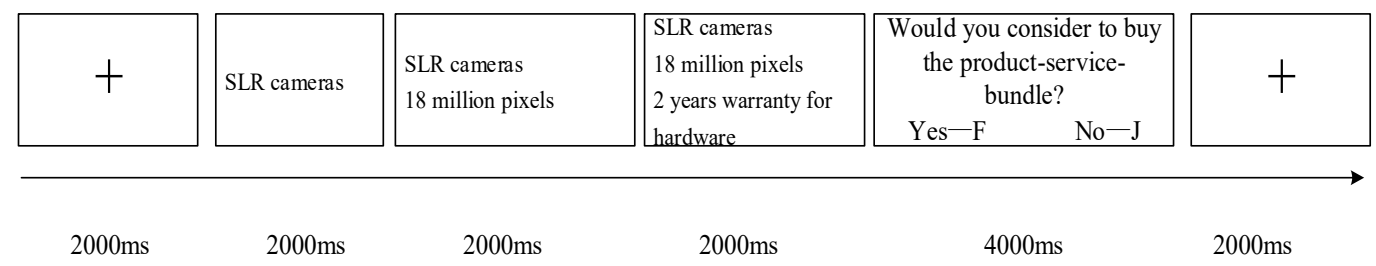

Figure 1. Illustration of the experimental task.

\subsection{Apparatus and Data Analysis}

Electroencephalograms (EEGs) measure voltage fluctuations on the scalp. The neuroeconomic studies in this paper collect data from individuals when stimuli were presented. The spatial orientation may be compared and transformed with the stimuli type. The equipment used in the experiment include EEG recording and analysis software (Net Station 4.1.1), and experiment implementation software (E-Prime 2.0). E-prime also collected all of the behavioral responses to verify the results; for instance, the relationship among customer response times and the cognitional valance of product-service bundle was examined. The EEG data processing included filtering, artifact detection, segmentation, averaging, and baseline correction.

Filtering. A zero-phase forward and reverse digital filter was used to low-pass filtered EEG data at $30 \mathrm{~Hz}$.

Artifact detection. Data editing and artifact rejection has been used for the statistical control of artifacts. Sensors contaminated across the session were identified and rejected when using the recording reference.

Segmentation. The continuous recording was broken into event-locked epochs (called segments) based on product-service bundles with superior levels of product and service, product-service bundles with superior levels of product and inferior levels of service, product-service bundles with inferior 
levels of product and superior levels of service, and product-service bundles with inferior levels of product and service.

Averaging. The segments are 1000-ms stimulus-locked epochs (from $200 \mathrm{~ms}$ pre-stimulus to $800 \mathrm{~ms}$ post-stimulus) to organize our data into categories so that we can average them or perform other operations on them. Average waveforms were calculated for each of the experimental cells (product-service bundle categories for superior and inferior product contents; product-service bundle categories for superior and inferior service contents) for each sensor and participant.

Baseline correction. Averaged ERP data were baseline corrected for pre-stimulus (200 ms) ERP activity. Then, channels in the parietal (Pz, P1, and P2), parietal-occipital ( $\mathrm{PO}_{\mathrm{z}}, \mathrm{PO}$, and $\left.\mathrm{PO} 4\right)$, and occipital $(\mathrm{Oz}, \mathrm{O} 1$, and $\mathrm{O} 2)$ regions were analyzed.

\section{Results}

\subsection{N170 Elicited by Product-Service Bundles with Different Product Contents}

The N170 (latency of 130-200 ms) was elicited for each product-service bundle stimulus. The brain topography at $170 \mathrm{~ms}$ has been presented in Figure 2 (a versus b; c versus d), including the channels related with cognition processing. Figure 3 shows the grand-averaged ERP waveforms of the PSS with the different product and service contents (Product-Service Bundle 1: superior product attributes and superior service level, Product-Service Bundle 2: inferior product attributes and superior service level; Product-Service Bundle 3: inferior product attributes and inferior service level, and Product-Service Bundle 4: superior product attributes and inferior service level) in the parietal-occipital $\left(\mathrm{PO}_{z}, \mathrm{PO}\right.$, and $\mathrm{PO} 4)$, parietal (Pz, P1, and P2), and occipital (Oz, O1, O2) channels. We compare the grand-averaged ERP waveforms of the product-service bundle with the comparison of Product-Service Bundle 1 and Product-Service Bundle 2, and the grand-averaged ERP waveforms of the product-service bundle with the comparison of Product-Service Bundle 3 and Product-Service Bundle 4.

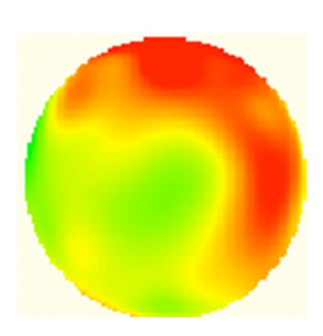

(a) Product-service-bundle with superior product and inferior service

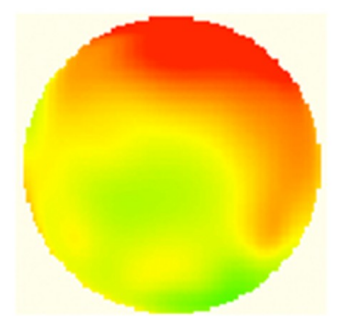

(c) Product-service-bundle with superior product and superior service

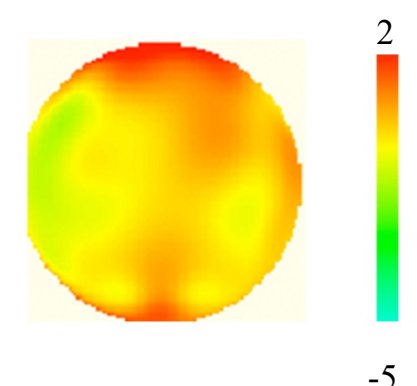

(b) Product-service-bundle with inferior product and inferior service

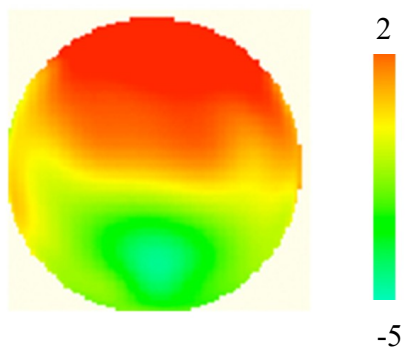

(d) Product-service-bundle with inferior product and superior service

Figure 2. Topographic plots of maximal amplitudes of the N170 elicited by product-service bundles with different product attribute and service levels $(170 \mathrm{~ms})$. 

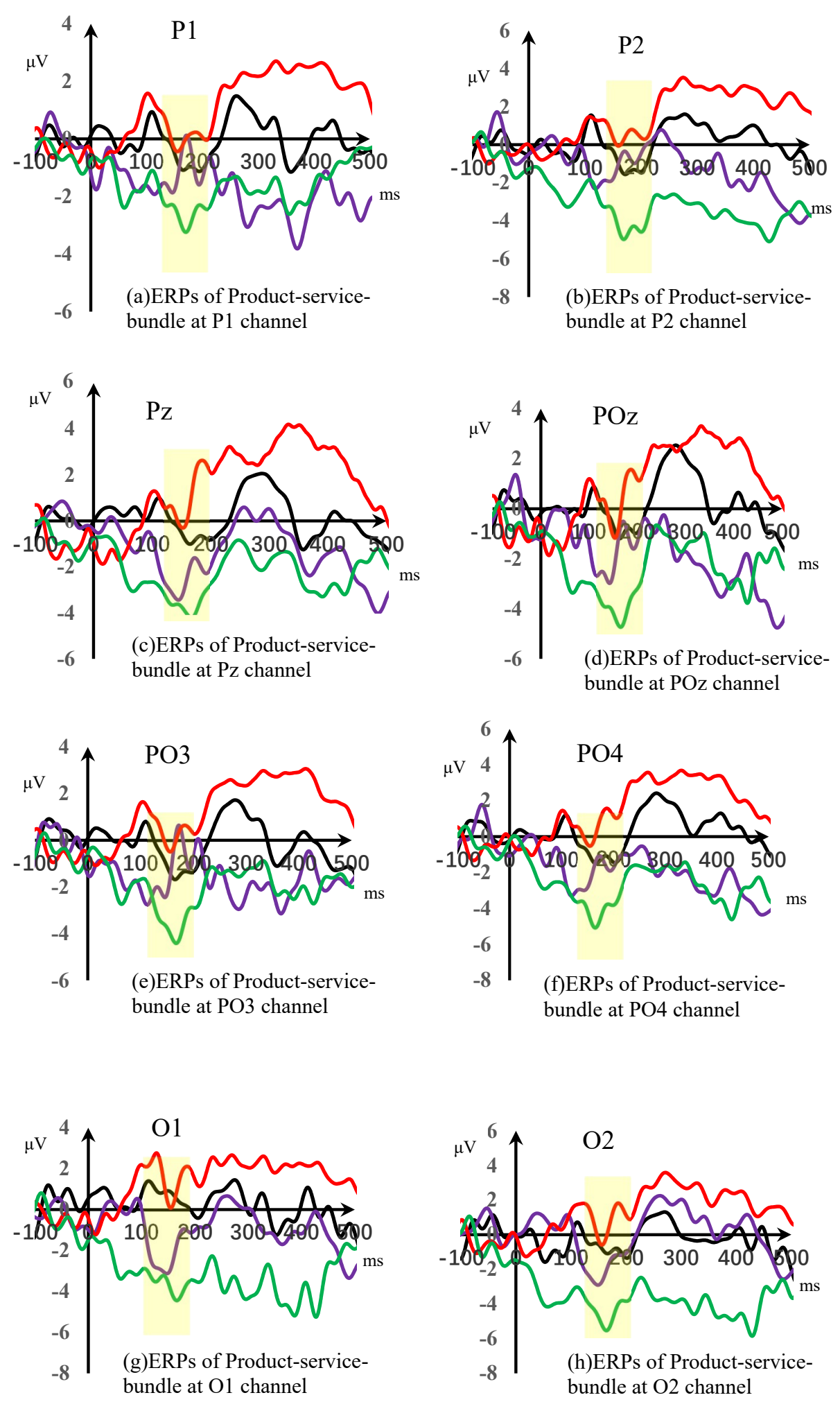

Figure 3. Cont. 

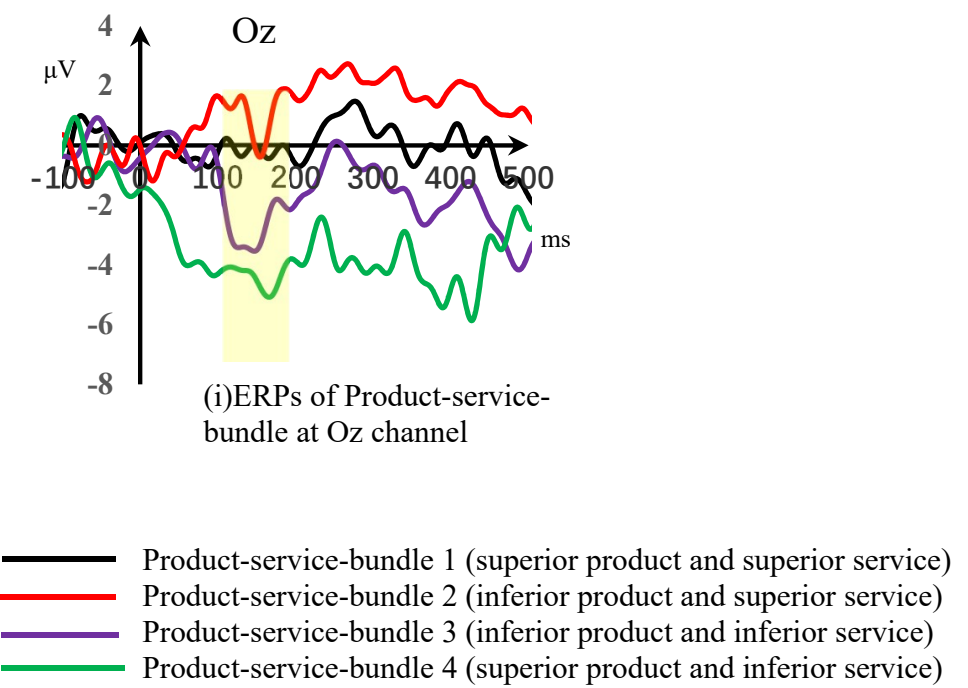

Figure 3. Grand averaged event-related potentials (ERPs) of product-service bundle with different product attributes and service levels at parietal, parietal-occipital, and occipital channels.

Figure 3 shows the ERPs at parietal, parietal-occipital, and occipital areas for product-service bundles with inferior products and services and product-service bundles with superior products and services. Between 130-200 ms, product-service bundles with superior products and inferior services elicited higher N170 than PSSs with inferior products and inferior services. Within the latency window for N170 (130-200 ms), we compared the average potentials elicited by product-service bundle stimuli for the two product levels with within-subjects repeated-measure ANOVA. The results indicated that the N170 levels were significantly different with respect to PSSs with inferior products and superior products with inferior service levels (Product-Service Bundle 3 versus Product-Service Bundle 4). Table 1 shows the mean amplitudes of the N170 in time windows of 130-200 ms, as well as the analysis of variance (ANOVA) results in these channels for product-service bundles with superior product attributes and inferior service levels, and product-service bundles with inferior product attributes and inferior service levels (Product-service bundle 3 versus Product-service bundle 4).

Table 1. Mean amplitudes of ERP and S.D. in parentheses in the time window of 130-200 ms and the results of ANOVA in Product-Service Bundle 3 and Product-Service Bundle 4 at different channels in the parietal (Pz, P1, and P2), parietal-occipital ( $\mathrm{PO}_{\mathrm{z}}, \mathrm{PO} 3$, and $\left.\mathrm{PO} 4\right)$, and occipital (Oz, O1, and O2) regions of the brain.

\begin{tabular}{ccccc}
\hline Channel & $\begin{array}{c}\text { Product-Service Bundle } \\
\text { with Superior Product and } \\
\text { Inferior Service }\end{array}$ & $\begin{array}{c}\text { Product-Service Bundle } \\
\text { with Inferior Product and } \\
\text { Inferior Service }\end{array}$ & F-Value & $p$-Value \\
\hline $\mathrm{Pz}$ & $-3.587(0.18)$ & $-2.45(0.41)$ & 78.271 & 0.000 \\
$\mathrm{P} 1$ & $-2.58(0.123)$ & $-1.09(0.45)$ & 141.787 & 0.000 \\
$\mathrm{P} 2$ & $-4.111(039)$ & $-1.123(0.35)$ & 429.149 & 0.000 \\
$\mathrm{PO} z$ & $-3.61(0.26)$ & $-1.70(0.69)$ & 207.503 & 0.000 \\
$\mathrm{PO} 3$ & $-3.61(0.26)$ & $-1.04(1.05)$ & 179.744 & 0.000 \\
$\mathrm{PO} 4$ & $-4.13(0.27)$ & $-2.06(0.49)$ & 201.996 & 0.000 \\
$\mathrm{Oz}$ & $-4.42(0.18)$ & $-2.63(0.48)$ & 173.463 & 0.000 \\
$\mathrm{O} 1$ & $-3.719(0.17)$ & $-1.93(0.81)$ & 117.078 & 0.000 \\
$\mathrm{O} 2$ & $-4.51(0.37)$ & $-1.91(0.51)$ & 275.776 & 0.000 \\
\hline
\end{tabular}

\subsection{N170 Elicited by Product-Service Bundle with Different Service Contents}

The N170 (latency of 130-200 ms) was elicited for each product-service bundle stimulus. As previously mentioned, Figure 3 shows the grand-averaged ERP waveforms of four product-service-bundles at parietal-occipital $\left(\mathrm{PO}_{\mathrm{z}}, \mathrm{PO} 3\right.$, and $\left.\mathrm{PO} 4\right)$, parietal $(\mathrm{Pz}, \mathrm{P} 1$, and $\mathrm{P} 2)$ and 
occipital $(\mathrm{Oz}, \mathrm{O} 1, \mathrm{O} 2)$ channels. We compared the grand-averaged ERP waveforms of the product-service bundle with the comparison of Product-Service Bundle 2 and Product-Service Bundle 3, and the grand-averaged ERP waveforms of the product-service bundle with the comparison of Product-Service Bundle 1 and Product-Service Bundle 4, which indicate the N170 variation induced by the changed service level. Figure 2 (a versus c; b versus d) shows the brain topography at $170 \mathrm{~ms}$, including that of the parietal, parietal-occipital and occipital channels, which indicates the importance of these brain regions for cognition processing. We compared the components of the ERPs elicited by the product-service bundle with different service levels when the product attribute remains constant. Figure 3 shows the ERPs at parietal, parietal-occipital, and occipital regions for product-service bundle with inferior service and product-service bundle with superior service. We compare the grand-averaged ERP waveforms of the product-service bundle with the comparison of Product-Service Bundle 2 and Product-Service Bundle 3, and the grand-averaged ERP waveforms of the product-service bundle with the comparison of Product-Service Bundle 1 and Product-Service Bundle 4.

No matter whether the product level was superior, the N170 obtained for the product-service bundle with inferior service content was significantly larger than that found for the product-service bundle with superior service content. In the groups with a superior product, the combination of a superior product and inferior service elicited a higher N170 than the product-service bundle with a superior product and superior service during $130-200 \mathrm{~ms}$. Therefore, the product-service bundle with inferior product combined with inferior service elicited an obvious N170, while the product-service bundle with inferior product and superior service elicited a tiny N170. Within the latency window for N170 (130-200 ms), we compared the average potentials with repeated-measure ANOVA. The N170 were significantly different with respect to the product-service bundle with superior product attributes and a superior service level, and the product-service bundle with superior product attributes and an inferior service level (Product-Service Bundle 1 versus Product-Service Bundle 4). Table 2 shows the mean amplitudes of the N170 in time windows of 130-200 ms, as well as the analysis of variance (ANOVA) results in these channels for the product-service bundle with superior and inferior product contents.

Table 2. The mean amplitudes of N170 and S.D. in parentheses in the time window of 130-200 ms and the results of ANOVA in Product-Service Bundle 1 and Product-Service Bundle 4 at different channels.

\begin{tabular}{ccccc}
\hline Channel & $\begin{array}{c}\text { Product-Service Bundle } \\
\text { with Superior Product and } \\
\text { Superior Service }\end{array}$ & $\begin{array}{c}\text { Product-Service Bundle } \\
\text { with Superior Product and } \\
\text { Inferior Service }\end{array}$ & F-Value & $p$-Value \\
\hline $\mathrm{Pz}$ & $-0.60(0.10)$ & $-3.587(0.18)$ & 1232.267 & 0.000 \\
$\mathrm{P} 1$ & $-0.73(0.17)$ & $-2.58(0.123)$ & 401.426 & 0.000 \\
$\mathrm{P} 2$ & $-0.92(0.34)$ & $-4.111(039)$ & 481.883 & 0.000 \\
$\mathrm{PO} Z$ & $-0.75(0.11)$ & $-3.61(0.26)$ & 1195.863 & 0.000 \\
$\mathrm{PO} 3$ & $-1.20(0.16)$ & $-3.61(0.26)$ & 499.824 & 0.000 \\
$\mathrm{PO} 4$ & $-1.05(0.12)$ & $-4.13(0.27)$ & 858.988 & 0.000 \\
$\mathrm{Oz}$ & $-0.22(0.03)$ & $-4.42(0.18)$ & 2981.466 & 0.000 \\
$\mathrm{O} 1$ & $-0.48(0.15)$ & $-3.719(0.17)$ & 1927.520 & 0.000 \\
$\mathrm{O} 2$ & $-0.82(0.07)$ & $-4.51(0.37)$ & 1123.022 & 0.000 \\
\hline
\end{tabular}

\subsection{Behavioral Data}

All of the participants made their decisions within the first $4000 \mathrm{~ms}$ after presentation of the product-service bundle. The total trials were valid. The data was calculated and tested with SPSS 18.0. The affirmed rate of the four product-service bundles is shown in Table 1. The results of repeated-measure ANOVA in Product-Service Bundle 3 (the product-service bundle with inferior product attributes and inferior service levels) and Product-Service Bundle 4 (product-service bundle with superior product attributes and inferior service levels) indicated that the product content had a highly significant effect on the buying decision. Table 3 shows the affirm rate of four product-service 
bundles. Additionally, the affirm rate of Product-Service Bundle 3 and Product-Service Bundle 4 showed the impact of the superior product on product-service bundle decision making. A higher affirmative decision rate was found for the product-service bundles with superior products than those with inferior products. When the product content level is high, the purchase rate is high; for instance, the purchase rate of the product-service bundle with a superior product and superior service was $73 \%$, while the purchase rate of the product-service bundle with a superior product and inferior service was $68.56 \%$, which is 1.2 times that of the bundle with inferior service. However, when the product is low-level, the purchase rate decreases sharply, no matter whether the service is high or low. The purchase rate of the product-service bundle with an inferior product and superior service is $21.59 \%$, while that of product-service bundle with an inferior product and inferior service is $27.7 \%$. When the product content is at the same superior level, the enhanced service may increase the product-service bundle purchase rate from $68.56 \%$ to $73 \%$. When the product content is at the same inferior level, the enhanced service cannot increase the purchase rate. When the product content is at the same superior level, the enhanced service may increase the purchase rate within a certain range.

Table 3. Affirm rate of four product-service bundles.

\begin{tabular}{ccccc}
\hline $\begin{array}{c}\text { Affirm Rate of } \\
\text { Product-Service } \\
\text { Bundle }\end{array}$ & $\begin{array}{c}\text { Product-Service } \\
\text { Bundle 1 (Superior } \\
\text { Product and Superior } \\
\text { Service) }\end{array}$ & $\begin{array}{c}\text { Product-Service } \\
\text { Bundle 2 (Inferior } \\
\text { Product and } \\
\text { Superior Service) }\end{array}$ & $\begin{array}{c}\text { Product-Service } \\
\text { Bundle 3 (Superior } \\
\text { Product and Inferior } \\
\text { Service) }\end{array}$ & $\begin{array}{c}\text { Product-Service } \\
\text { Bundle 4 (Inferior } \\
\text { Product and } \\
\text { Inferior Service) }\end{array}$ \\
\hline Mean value & 0.730 & 0.216 & 0.687 & 0.277 \\
Variance & 0.041 & 0.028 & 0.043 & 0.057 \\
\hline
\end{tabular}

\section{Discussion}

\subsection{Theoretical Contributions}

This paper adopts the neuromarketing approach to indicate the PSS component requirement sensitivity. The larger N170 amplitude was triggered by PSSs with a superior product, although the N170 component was generated among all of the parietal and parietal-occipital regions in all of the PSSs. Furthermore, the N170 was significantly larger, with a superior product than in a PSS with an inferior product, no matter whether the service level was high or low. The research explained the neurological activities when the consumer perceived the PSS and presented the function of product component in PSS decision making. In addition, the purchase rate of PSSs with superior products was significantly larger than PSSs with inferior products, no matter whether the service level was high or low. When the product level was high, the purchase rate was high. For example, the purchase rate of PSSs with superior products and superior service was 73\%, while the purchase rate of PSSs with superior products and inferior service was $68.56 \%$, which was 1.2 of the low service level. However, when the product was low-level, the purchase rate decreased sharply, no matter the quality of the service. The purchase rate of PSSs with inferior products and superior service was $21.59 \%$, while that of PSSs with inferior products and inferior services was $27.7 \%$. The promoting effect of service is not obvious when the product attributes are at an inferior level in product-oriented PSSs. The enlarged amplitude of N170, which was elicited by PSSs with superior product attributes, may be in line with the expectations of consumers, which indicate more similarity with customer requirements. The complementary and alternative relationship between the product attribute and service in PSSs may be the main reason that the amplitude and purchase rate was not the lowest of the four PSS conditions.

N170 can be induced not only by faces but also by other stimuli, such as cars, houses, shoes, furniture, tools, road signs, flowers, and printed words. The larger N170 elicited by faces may be influenced by their expertise in recognizing faces. The N170 may be associated with the object category information processing: the more similarity and familiarity with the visual mechanism, the larger the N170 amplitude. Superior product attributes in product-oriented PSSs elicited a high N170, which indicated the customer's expertise in recognizing product attributes. In addition, the high 
purchase rate of PSSs with superior product attributes presented the customer's demand in PSSs. Therefore, consumers' demands for product attributes are more sensitive than those for service in PSSs. The required sensitivity of neural mechanisms in PSSs has been indicated by the appearance of N170, which is related with the cognitive processing of familiarity and similarity. No matter the service level, the N170 obtained for PSSs with superior products was significantly larger than that found for PSSs with inferior products. In previous studies, scholars confirmed that consumers' expected product attributes can induce greater ERP amplitudes [46]. Since high product attributes may be more in line with consumer expectations, the superior products may elicit higher amplitude than inferior products and various services.

\subsection{Managerial Implications}

This paper has several implications for PSS innovation and the improvement of service design. Customer requirements are related to the product and service design in PSSs. To realize the preferable PSS for customers, the required sensitivity of each PSS component should be identified. In order to evaluate the perceived value of different degrees of PSS, the product component and service component can be divided into superior and inferior levels based on the pre-test. Then, the PSS stimuli were classified by the combination of the two levels of the product and service components, including PSSs with an inferior or superior product component and an inferior or superior service component.

When the product component is used to provide the service in the PSS, the superior service component occurs in order to support the products. When the one component in a PSS (product content or service content) is at a constant level (superior or inferior), we compared the PSS purchase rate with the variance of the other component (service content, product content) in order to identify the key component in the PSS. The purchase rate of PSSs with superior product content was significantly larger than that of PSSs with inferior product content, no matter whether the service level was high or low. The product component played a key role in providing the specific service function and clarifying the component relationship in the PSS. We have confirmed that the product content plays a major role in product-oriented decision making, according to our behavioral data. When the product content is at an inferior level, enhanced service cannot increase the purchase rate. When the product content is at a superior level, the enhanced service may increase the purchase rate within a certain range. The product-oriented PSS design is proposed to study the integration problem of product and service. The functionality and performance of products in corresponding PSSs may be prompted by the service that is offered in product-oriented PSSs, which tries to meet customer requirements.

One important facet of this work has investigated the extent of the impact of component requirement sensitivity on PSS decision making. This work showed that the cognitional ERP component is evoked by the services and products portfolio in the parietal-occipital, parietal, and occipital regions, particularly regarding the larger N170 values elicited by the PSS with superior product components. According to the pre-test, we divided the PSSs into four combinations, including PSSs with inferior or superior product content and inferior or superior service content, in order to identify the key component that may induce significant variation in the purchase rate. When one component in the PSS (product content or service content) was at a constant level (superior or inferior), we compared the PSS purchase rate with the variance of the other component (service content, product content) in the PSS. It is confirmed that the product content plays a great role in the product-oriented decision making according to the behavioral data. The purchase rate of the PSS with superior product content was significantly larger than that of the PSS with inferior product content, no matter whether the service level high or low. When the product content was at an inferior level, enhanced service could not increase the purchase rate. When the product content was at a superior level, enhanced service may increase the purchase rate within a certain range. Moreover, the neural mechanisms of PSSs' requirement sensitivity have been indicated by the appearance of N170 related with the cognition processing of familiarity and similarity. No matter the service level, the N170 obtained for PSSs with superior product contents was significantly larger than that found for PSSs with inferior product 
contents. The promoting effect of service is not obvious when the product attributes are at an inferior level in product-oriented PSSs. In conclusion, the sensitivity component of the PSS may have elicited higher N170 values. The conclusion may guide corporations in better understanding the relationship between the components in PSS and innovate PSS based on customer requirements. According to the significantly higher purchase rate of PSSs with superior product components, this work confirms that the consumer requirements regarding the product component have a higher priority than the service component in product-oriented PSSs. The result may inform the innovation and design of PSSs based on customer cognition and potential requirements.

\subsection{Limitations and Future Research}

In this paper the product-service bundle requirement was divided into two categories, intrinsic and extrinsic, by the neuromarketing method. The limitation of the present study is the difference between the laboratory and the Internet in the online shopping scene. Due to the variety of commodity items, the stimuli presented in the experiment has been limited. Although we selected appropriate products in three price ranges, the study would obtain more verification from other kinds of goods. Additionally, a substantial limitation of the design is its low power, which was due to the student sample size. Although significant correlations were found between customer emotions and decision making, an additional analysis was conducted to examine differences in decision making while dividing the sample into two groups (participants who are students versus non-students). When the services prompt competitive advantage within a certain range, it is important for the corporation to balance the perceived value and cost in a product-service bundle.

The within-subject experimental design adopted in this paper also inspires the between-subject experimental design based on customer differentiation. For instance, this study implies that consumer purchasing experience and cognitive competence are associated with consumption patterns and choices, which may promote the study of customer requirements and guide the research of product-service bundle marketing. Further study may focus on the component requirement sensitivity in result-oriented PSS and utility-oriented PSS when the ownership of the product is not transferred in the process of trading. Further study may directly examine ERPs correlated to product-service bundle evaluations when consumers make buying decisions. In addition, according to the component requirement sensitivity in the product-service bundles, the preliminary study of the relationship between products and services in product-service bundles has been elucidated. The reason why product-service bundles with superior products and superior service cannot elicit the highest ERP amplitude may reveal a complementary and alternative relationship between a product and a service in PSSs. To improve PSS development and innovation, further studies related to this topic should be conducted in the future.

\section{Conclusions}

This paper adopted the neuromarketing approach to indicate the component requirement sensitivity in product-service bundles. An ERP component, N170, was presented among the parietal and parietal-occipital regions in product-service bundle stimulus, but the larger N170 amplitude was only generated by the product-service bundle with a superior product. Furthermore, the N170 was significantly larger with a superior product than with a product-service bundle that featured an inferior product, no matter whether the service level was high or low. The findings indicated the brain activities and neurological processing mechanisms when customers purchase product-service bundles, showing the brain regions that manage the attention modulation and PSS performance evaluation. In addition, the purchase rate of product-service bundles with superior products was significantly larger than product-service bundles with inferior products, no matter whether the service level was high or low. When the product level is high, the purchase rate is high. For example, the purchase rate of the product-service bundle with superior product and superior service was $73 \%$, while the purchase rate of the product-service bundle with superior product and inferior service was $68.56 \%$, which was 
1.2 times that of the product-service bundles with low service and product levels. However, when the product was low-level, the purchase rate decreased sharply, no matter the quality of the service. The purchase rate of the product-service bundle with an inferior product and superior service was $21.59 \%$, while that of the product-service bundle with inferior product and inferior service was $27.7 \%$. The promoting effect of service is not obvious when the product attributes are at an inferior level in a product-oriented product-service bundle. The enlarged amplitude of N170, which was elicited by a product-service bundle with superior product attributes, may be in line with the expectations of consumers, which indicate more similarity with customer requirements. The complementary and alternative relationship between the product attribute and service in product-service bundles may be the main reason that the amplitude and purchase rate was not the lowest of the four product-service bundle scenarios.

The larger N170 elicited by faces may be influenced by their expertise in recognizing faces. The N170 may be associated with the object category information processing: the more similarity and familiarity with the visual mechanism, the larger the N170 amplitude. Superior product attributes in product-oriented product-service bundles elicited a high N170 amplitude, which indicated the customer's expertise in recognizing product attributes. In addition, the high purchase rate of the product-service bundle with superior product attributes presented the customer's demand regarding product-service bundles. Therefore, consumers' demands for product attributes are more sensitive than those for service in product-service bundles. The required sensitivity of neural mechanisms in product-service bundles has been indicated by the appearance of N170, which is related with the cognitive processing of familiarity and similarity. No matter the service level, the N170 obtained for product-service bundles with superior products was significantly larger than that found for product-service bundles with inferior products.

Author Contributions: J.W. and M.Z. presented the research idea and the method; H.Z. recorded and provided the experiment data; M.Z. wrote the paper; and G.Z. provided the resources in the experiment.

Funding: The work reported in this paper was supported by Postdoctoral Science Foundation of China (No. 2017M620580); National Natural Science Foundation of China (No. 71332003); and Special Foundation of Heilongjiang University (No. HDYJW201802).

Acknowledgments: Thanks for the technical support from the behavioral and psychological laboratory in Beihang University. I really appreciate my supervisor, Wang Jing, for his encouragement and guidance. Professor Wang were engaging in the field when he was alive.

Conflicts of Interest: The authors declare no conflict of interest.

\section{References}

1. Reim, W.; Parida, V.; Örtqvist, D. Product-Service Systems (PSS) business models and tactics-a systematic literature review. J. Clean. Prod. 2015, 97, 61-75.

2. Neely, A. Exploring the financial consequences of the servitization of manufacturing. Oper. Manag. Res. 2008, 1, 103-118.

3. Sun, J.; Chai, N.; Pi, G.; Zhang, Z.; Fan, B. Modularization of product service system based on functional requirement. Procedia CIRP 2017, 64, 301-305. [CrossRef]

4. Kubota, Y.; Murakami, F.; Kimita, K.; Shimomura, Y. The task to design highly service-oriented Product-Service System. Procedia CIRP 2017, 60, 416-421.

5. Tukker, A. Product services for a resource-efficient and circular economy-A review. J. Clean. Prod. 2015, 97, 76-91. [CrossRef]

6. Mont, O.K. Clarifying the concept of product service system. J. Clean. Prod. 2002, 10, 237-245. [CrossRef]

7. Zhu, H.; Li, J.; Gao, J.; Lu, W. Research on integrated product service system driven by customer value based on ontology technology. Kybernetes 2017, 46, 1039-1051. [CrossRef]

8. Rexfelt, O.; Hiortaf, O.V. Consumer acceptance of product service systems-designing for relative advantage and uncertainty reductions. J. Manuf. Technol. Manag. 2009, 20, 674-699.

9. Song, W. Requirement management for product-service systems: Status review and future trends. Comput. Ind. 2017, 85, 11-22. 
10. Elgammal, A.; Papazoglou, M.; Krämer, B.; Constantinescu, C. Design for Customization: A New Paradigm for Product-Service System Development. Procedia CIRP 2017, 64, 345-350.

11. Tellis, G.; Stremersch, S. Strategic bundling of products and prices: A new synthesis for marketing. J. Mark. $2002,66,72-79$.

12. Cook, M.B.; Bhamra, T.A.; Lemon, M. The transfer and application of Product Service Systems: From academic to UK manufacturing firms. J. Clean. Prod. 2006, 14, 1455-1465. [CrossRef]

13. Bruno, R.; Corentin, J. Does physical interstimulus variance account for early electrophysiological face sensitive responses in the human brain? Ten lessons on the N170. Neuroimage 2008, 39, 1959-1979.

14. Mangun, G.R.; Hillyard, S.A. Electrophysiological studies of visual selective attention in humans. In The Neurobiological Foundations of Higher Cognitive Function; Scheibel, A.B., Wechsler, A., Eds.; Guilford Press: New York, NY, USA, 1998; pp. 271-296.

15. Russell, J.A. Emotion, core affect, and psychological construction. Cognit. Emot. 2009, 23, 1259-1283.

16. Warde, A. Consumption and theories of practice. J. Consum. Cult. 2005, 5, 131-153.

17. Wang, Y.; Sun, L.; Qu, R.; Li, G. Price and Service Competition with Maintenance Service Bundling. J. Syst. Sci. Syst. Eng. 2015, 24, 168-189. [CrossRef]

18. Tukker, A.; Tischner, U. Product-services as a research field: Past, present and future. Reflections from a decade of research. J. Clean. Prod. 2006, 14, 1552-1556. [CrossRef]

19. Xing, K.; Wang, H.F.; Qian, W. A sustainability-oriented multi-dimensional value assessment model for product-service development. Int. J. Prod. Res. 2013, 51, 5908-5933. [CrossRef]

20. Mylan, J. Understanding the diffusion of sustainable product-service systems: Insight from the sociology of consumption and practice theory. J. Clean. Prod. 2015, 97, 13-20. [CrossRef]

21. Nijssen, E.J.; Hillebrand, B.; Vermeulen, P.A.M.; Kemp, R.G.M. Exploring product and service innovation similarities and differences. Int. J. Prod. Res. 2006, 23, 241-251. [CrossRef]

22. Yao, H.; Jin, Y.; Yan, J.Q. Qualitative and quantitative analysis of product functional requirements. Chin. J. Mech. Eng. 2010, 46, 191-198.

23. Cook, M. Fluid transitions to more sustainable product service systems. Environ. Innov. Soc. Transit. 2014, 12, 1-13. [CrossRef]

24. Alessandra, D. Differential impairment of cognitive and affective mentalizing abilities in neurodegenerative dementias: Evidence from behavioral variant of frontotemporal dementia. alzheimer's disease, and mild cognitive impairment. J. Alzheimers Dis. 2016, 50, 1011-1022.

25. Zhao, M.; Wang, J.; Zhao, G. Application of frontal EEG asymmetry to customer emotional value perception in PSS. Int. J. Inf. Syst. Chang. Manag. 2017, 9, 106-124.

26. Zhao, M.; Wang, J.; Han, W. The impact of emotional involvement on online service buying decisions: An event-related potentials perspective. Neuroreport 2015, 26, 995-1002. [PubMed]

27. Wang, J.; Zhao, M.; Zhao, G. The impact of customer cognitive competence on online service decision-making: An event-related potentials perspective. Serv. Ind. J. 2017, 37, 363-380. [CrossRef]

28. Bertoni, A.; Larsson, T. Data mining in product service systems design: Literature review and research questions. Procedia CIRP 2017, 64, 306-311.

29. Rintamäki, T.; Kuusela, H.; Mitronen, L. Identifying competitive customer value propositions in retailing. Manag. Serv. Qual. 2007, 16, 621-634.

30. Simonin, B.L.; Ruth, J.A. Is accompany known by the company it keeps? Assessing the spill over effects of brand alliances on consumer brand attitudes. J. Mark. Res. 1998, 35, 30-42.

31. Catulli, M.; Cook, M.; Potter, S. Consuming use orientated product service systems: A consumer culture theory perspective. J. Clean. Prod. 2017, 141, 1186-1193.

32. Gummesson, E.; Grönroos, C. The emergence of the new service marketing: Nordic school perspectives. J. Serv. Manag. 2012, 23, 479-497.

33. Tontini, G. Integrating the Kano Model and QFD for Designing New Products. Total Qual. Manag. Bus. Excell. 2007, 18, 599-612.

34. Lee, Y.C.; Huang, S.Y. A New Fuzzy Concept Approach for Kano's Model. Expert Syst. Appl. 2009, 36, 4479-4484. [CrossRef]

35. Gustafsson, A.; Högström, C.; Radnor, Z.; Friman, M.; Heinonen, K.; Jaakkola, E.; Mele, C. Developing service research-paving the way to transdisciplinary research. J. Serv. Manag. 2016, 27, 9-20. 
36. Cauquil, A.S.; Edmonds, G.E.; Taylor, M.J. Is the face-sensitive N170 the only ERP not affected by selective attention? " Neuroreport 2000, 11, 2167-2171. [CrossRef]

37. Ince, R.A.A. The deceptively simple N170 reflects network information processing mechanisms involving visual feature coding and transfer across hemispheres. Cerebral Cortex 2016, 26, 4123-4135.

38. Yang, H.; Zhao, J.; Gaspar, C.M.; Chen, W.; Tan, Y.; Weng, X. Selectivity of N170 for visual words in the right hemisphere: Evidence from single-trial analysis. Psychophysiology 2017, 54, 1128-1137. [CrossRef]

39. Jang, S.C.; Namkung, Y. Perceived quality, emotions, and behavioral intentions: Application of an extended Mehrabian-Russell model to restaurants. J. Bus. Res. 2009, 62, 451-460. [CrossRef]

40. Benoit, S.; Scherschel, K.; Ates, Z.; Nasr, L.; Kandampully, J. Showcasing the diversity of service research: Theories, methods, and success of service articles. J. Serv. Manag. 2017, 28, 810-836.

41. Babin, B.J.; James, W.J. A brief retrospective and introspective on value. Eur. Bus. Rev. 2010, 22, 471-478.

42. Bardhi, F.; Eckhardt, G.M. Access-based consumption: The case of car sharing. J. Consum. Res. 2012, 39, 1-18. [CrossRef]

43. Beuren, F.H.; Ferreira, M.G.G.; Miguel, P.A.C. Product-service systems: A literature review on integrated products and services. J. Clean. Prod. 2013, 47, 222-231. [CrossRef]

44. Chen, Y. Possession and access: Consumer desires and value perceptions regarding contemporary art collection and exhibit visits. J. Consum. Res. 2009, 35, 925-940. [CrossRef]

45. Khandeparkar, $\mathrm{K}$. The role of complementarity and partner brand price level in new product introduction strategy using bundle offers: A study on the Quality perception of bundle components. J. Retail. Consum. Serv. 2014, 21, 992-1000. [CrossRef]

46. Wang, J.; Han, W. The impact of perceived quality on online buying decisions: An event-related potentials perspective. Neuroreport 2014, 25, 1091-1098. [CrossRef] [PubMed]

(C) 2019 by the authors. Licensee MDPI, Basel, Switzerland. This article is an open access article distributed under the terms and conditions of the Creative Commons Attribution (CC BY) license (http:/ / creativecommons.org/licenses/by/4.0/). 